\title{
Ultramicroscopic Aspects of the Conversion of Fibroblasts to Chondrocytes in the Mouse Dorsal Subfascia Induced by Bone Morphogenetic Protein (BMP)*
}

\author{
Michihiro Yabu $^{1}$, Kunio TaKaOKa ${ }^{2}$, Jun Hashimoto ${ }^{2}$ and Hisao Fujita ${ }^{1}$ \\ Department of Anatomy ${ }^{1}$ and Department of Orthopaedic Surgery ${ }^{2}$, Osaka University Medical School, Osaka, Japan
}

Received July 23, 1990

Summary. Direct conversion of typical fibroblasts to chondrocytes in the mouse fibrous connective tissue induced by bone morphogenetic protein (BMP) was observed by light as well as electron microscopy. A pellet containing BMP obtained from a murine osteosarcoma was transplanted into the dorsal subfascia of 5 week-old mice. Until 3 days after implantation of BMP, all the connective tissue cells in the pellet region of the dorsal subfascia showed the fine structural features of typical fibroblasts. The cells in the pellet region changed their shape from spindle-like to polygonal by 5 days after implantation. At this time, small vacuoles $150-450 \mathrm{~nm}$ and vesicles $40-60 \mathrm{~nm}$ in diameter, containing a homogeneous substance of low electron density, appeared in the cytoplasm of the cells. A small amount of extracellular substance, showing metachromasia by toluidine blue staining, was seen around the cells. Moreover, autoradiography of ${ }^{35} \mathrm{~S}$ revealed the uptake of sulfur by the cells and its accumulation in the extracellular substance around the cells in the pellet region at 5 days. The rough endoplasmic reticulum and Golgi apparatus increasingly developed with time and after 7 days both elements were distributed throughout the cytoplasm. The cytoplasmic small vacuoles and vesicles also increased in number with time, and the metachromatic extracellular substance containing fine filamentous meshwork and many tiny particles, which was regarded as the matrix of cartilage, also increased rapidly in amount. By 9 days, the cells in the pellet region became oval or round in shape, showing many short cytoplasmic processes. This finding indicates that the fibroblasts in the BMP pellet region transform to chondroblasts at least by 5 days after implantation, and become typical chondrocytes by 9 days.
In regard to the origin of chondrocytes, it has been believed by many anatomists and pathologists that they are derived from undifferentiated mesenchymal cells even in adult animals. The name "undifferentiated mesenchymal cell" in a strict sense should be used for a stem cell having the potency to differentiate into almost all kinds of connective tissue cells, chondrocyte, osteocyte and blood cells. However, in the connective tissue of adult animals, it is

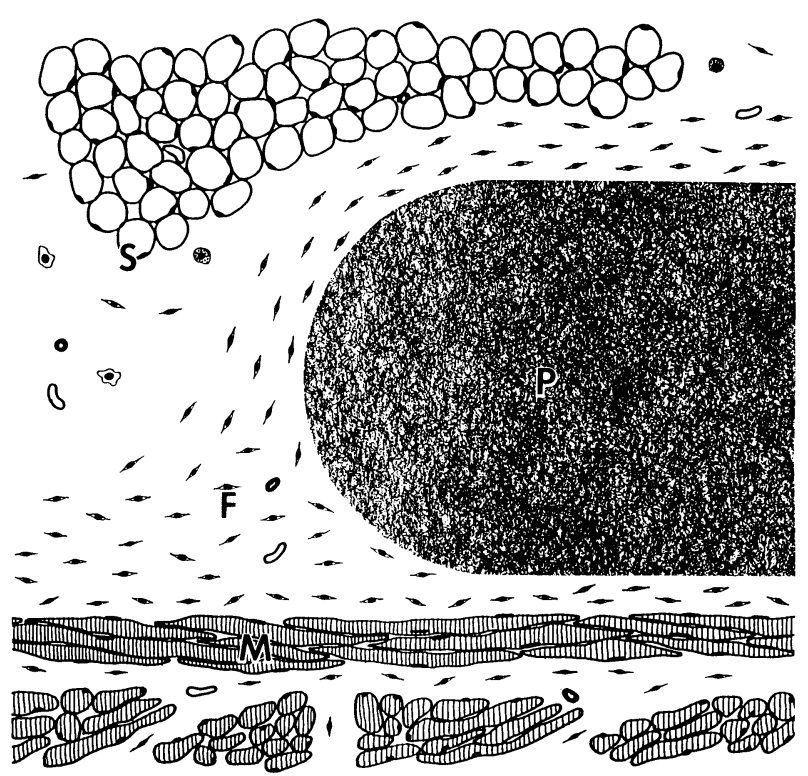

Fig. 1. Diagram showing the location of the BMP pellet. The pellet is transplanted into the subfascia, where abundant fibroblasts reside. $P$ BMP pellet, $F$ fascia, $M$ muscle, $S$ subcutis.

\footnotetext{
*This study was supported by a grant from the Ministry of Education, Science and Culture, Japan.
} 
difficult to find a typical undifferentiated mesenchymal cell showing poorly developed cell organelles and abundant free ribosomes.

In this context, we noticed that a typical fibroblast could change to a typical chondrocyte during our investigations using a special factor called bone morphogenetic protein (BMP). The factor, derived from an osteosarcoma, has been reported to be a glycoprotein about 20,000 in molecular weight (TA. KAOKA et al., 1981) and inducing ossification in the connective tissue (AMitANi et al., 1974).

This communication concerns the detailed description of the fine structural changes during the conversion of a typical fibroblast to a chondrocyte and discussion about the potency of the fibroblast to differentiate into several kinds of cells.

\section{MATERIALS AND METHODS}

\section{Light and electron microscopy of chondrogenesis in mouse dorsal subfascia}

As previously reported (TAKAOKA et al., 1988), partially purified bone morphogenetic protein (BMP) from a murine osteosarcoma and Type I collagen from the calf skin were thoroughly mixed and lyophilized. Then the disc-shaped pellet, $5 \mathrm{~mm}$ in diameter and $1 \mathrm{~mm}$ in height, was prepared.

The pellet was transplanted into the dorsal subfascia of 5 week-old ICR mice (Fig. 1), and subfascial tissues, removed 3, 5, 7 and 9 days after transplanta-

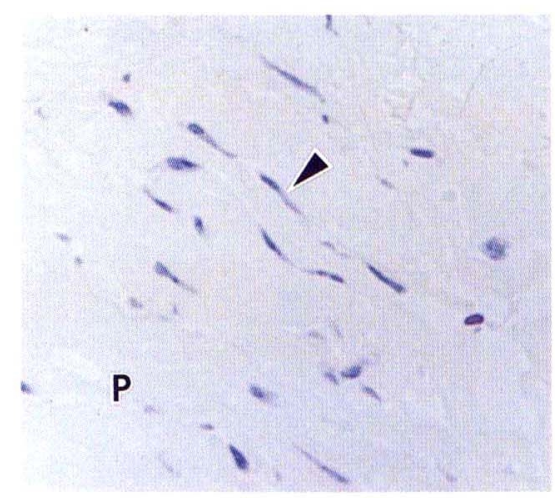

a pellet region. a. Three days after transplantation of the pellet consisting of collagen and BMP, many fibroblasts (arrowhead), spindle-like in shape, are seen in the pellet region $(P)$. b. At 7 days, the cells (arrowhead) in the pellet region are polygonal in shape and are surrounded by a metachromatic matrix $(M)$ being stained red purple. c. At 9 days, most of the cells (arrowhead) in the pellet region are round in shape and around them is a large amount of matrix $(M)$ showing metachromasia. $\times 360$

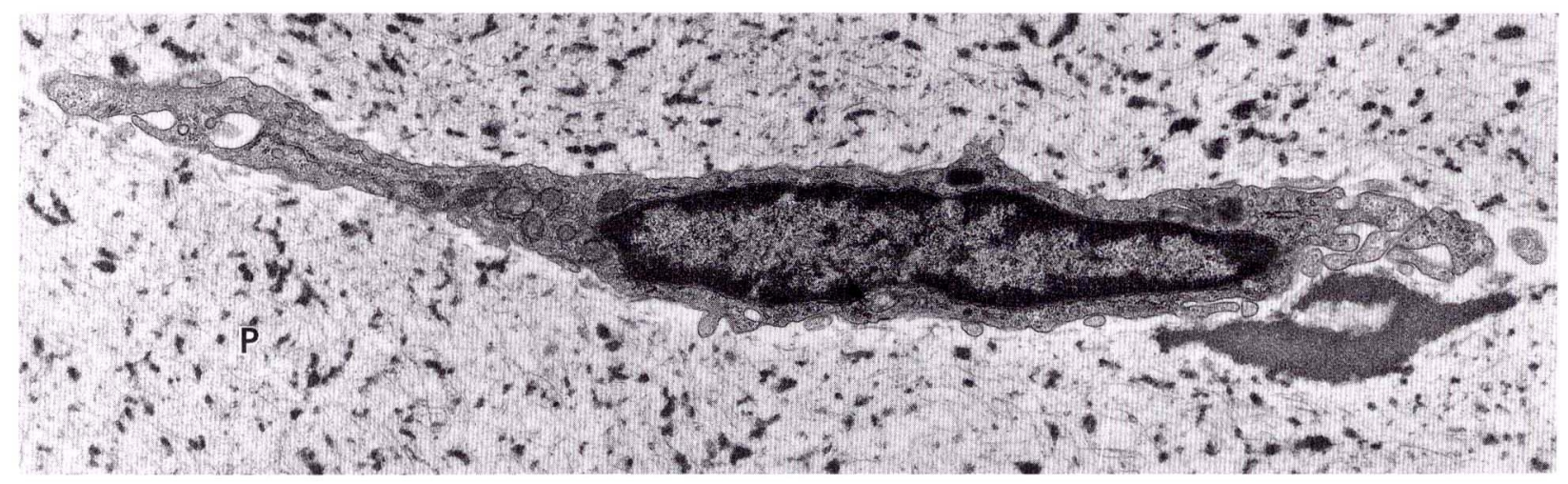

Fig. 3. Electron micrograph of a cell in the BMP pellet region at 3 days. The cell shows the ultrastructural characteristics of the typical fibroblast; it is elongated in shape and the rough endoplasmic reticulum is fairly well developed. Around the cell is a part of the pellet $(P)$ consisting of the fibrillar collagen constituent and granular BMP component. $\times 10,500$ 
tion of the BMP pellet, were examined by light as well as electron microscopy.

As the control, the pellet consisting only of collagen from the calf skin was transplanted in the same way, and the tissues were observed after 7 days. The intact dorsal subfascial tissues of the mice were also examined.

For light microscopic observations, the specimens

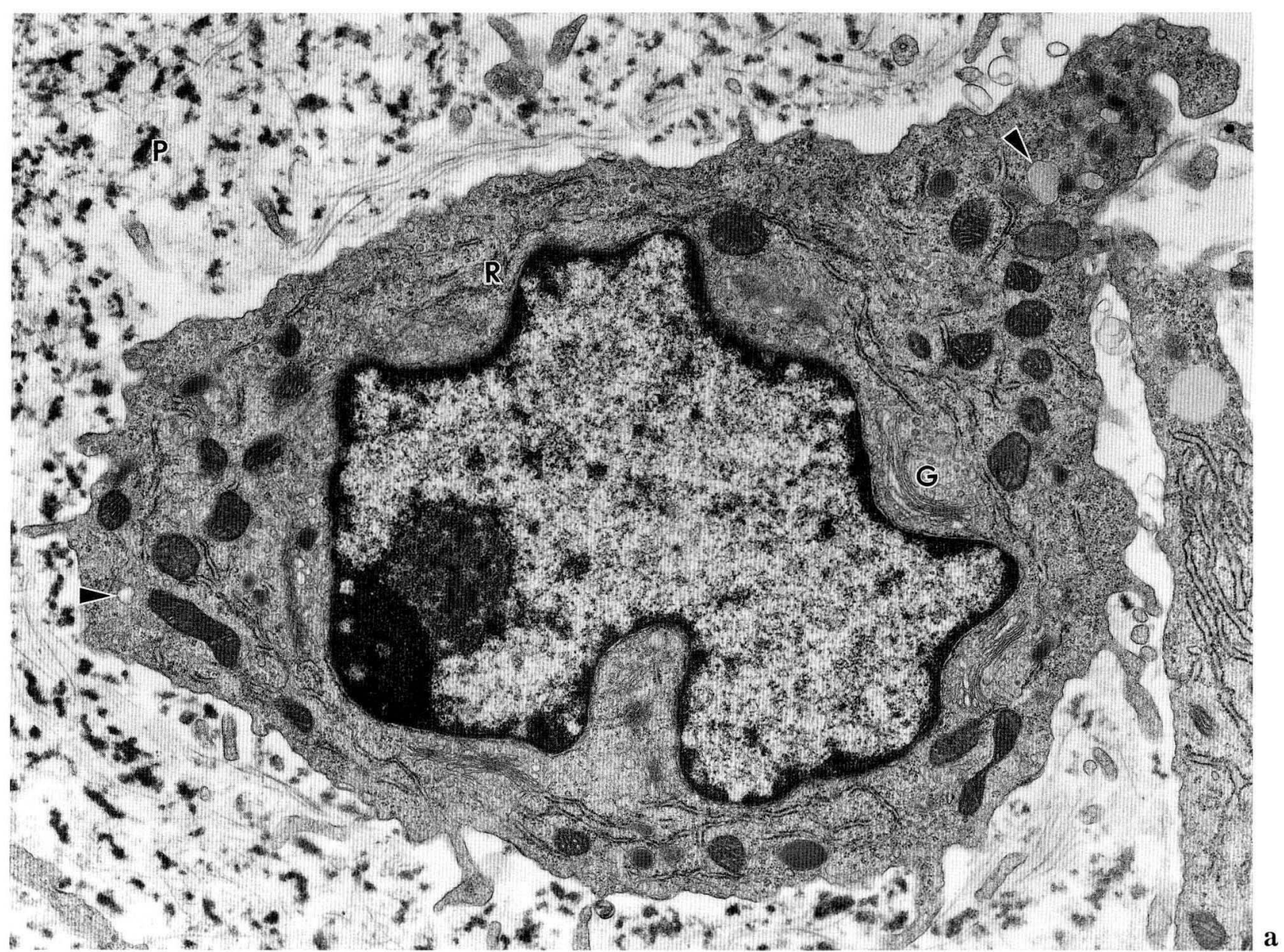

Fig. 4. Electron micrographs of cells in the BMP pellet region at 5 days. a. The cell is polygonal in shape and the rough endoplasmic reticulum $(R)$ and Golgi apparatus $(G)$ are developed better than the fibroblast at 3 days. Note that a small number of vacuoles (arrowheads) containing a homogeneous substance of low electron density appear in the cytoplasm of the cell. Around the cell is a part of the BMP pellet $(P) . \times 12,000$. b. A small amount of extracellular matrix $(M)$ of low electron density, corresponding to the metachromatic region by light microscopy is seen between the cell and the BMP pellet $(P) . \times 29,000$

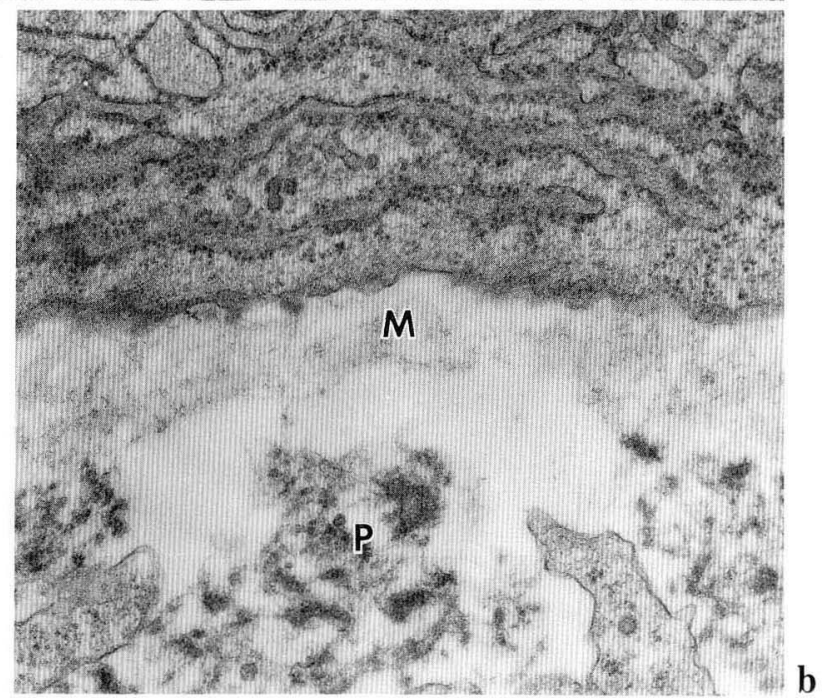


were fixed in 10\% formalin overnight at room temperature, dehydrated through an ethanol gradient, and embedded in JB4. Sections, $2.5 \mu \mathrm{m}$ thick, were cut and observed with a light microscope after hematoxylin-eosin or toluidine blue staining.

For electron microscope observations, the specimens were fixed in $2.5 \%$ glutaraldehyde solution buffered at $\mathrm{pH} 7.4$ with $0.1 \mathrm{M}$ Millonig's phosphate buffer for $2 \mathrm{~h}$ at $4^{\circ} \mathrm{C}$, and postfixed in $1 \%$ osmium tetroxide solution buffered at $\mathrm{pH} 7.4$ with the same buffer for $2 \mathrm{~h}$ at $4^{\circ} \mathrm{C}$. After washing several times in $10 \%$ sucrose solution, they were stained en bloc in aqueous $3 \%$ uranyl acetate. Dehydrated through an ethanol gradiant, they were embedded in Epon 812 .
Ultrathin sections, cut and stained with uranyl acetate and lead citrate, were observed with a JEOL $1200 \mathrm{EX}$ electron microscope.

\section{Light microscopic autoradiography of ${ }^{35} \mathrm{~S}$}

In order to investigate the production of the cartilage matrix rich in proteoglycan, autoradiography of ${ }^{35} \mathrm{~S}$ was performed. A pellet consisting only of semipurified BMP from a murine osteosarcoma was transplanted into the dorsal subfascia of 5 week-old ICR mice. The mice were injected intraperitoneally with $40 \mu \mathrm{Ci} / \mathrm{g}$ body weight of $\mathrm{Na}_{2}{ }^{35} \mathrm{SO}_{4}$ (Amersham, Tokyo) in normal saline solution $3 \mathrm{~h}$ before sacrifice at 3 and 5 days after transplantation of the BMP

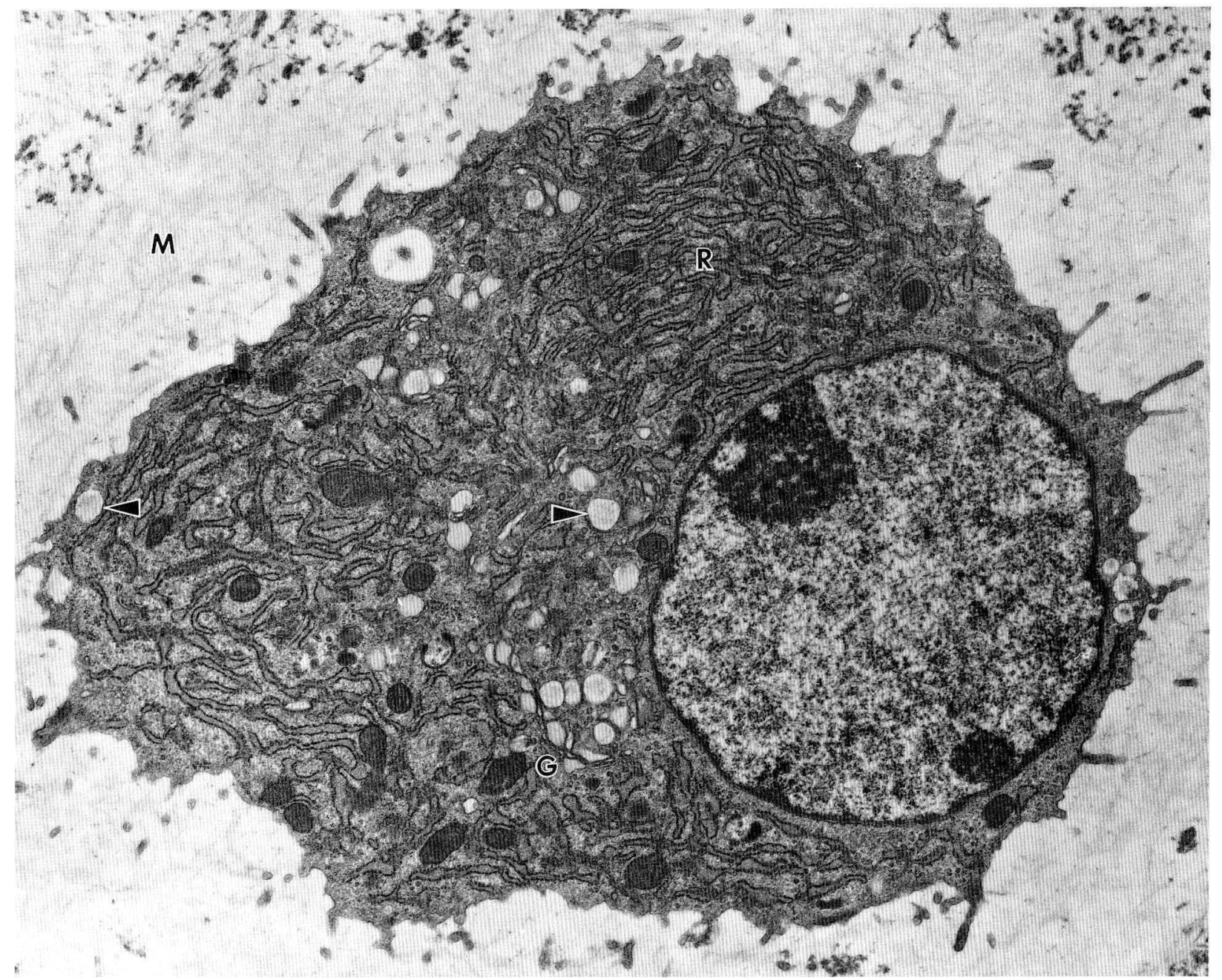

Fig. 5. Electron micrograph of a cell in the BMP pellet region at 7 days. The polygonal cell is surrounded by an abundant extracellular cartilagenous matrix $(M)$ containing collagenous fibrils and many electron-dense particles. The cell, extending many short processes into the surrounding matrix, has very well-developed rough endoplasmic reticulum $(R)$ and Golgi apparatus $(G)$ as well as many vacuoles (arrowheads) containing a homogeneous substance of low electron density. $\times 10,000$ 
pellet. After sacrifice the subfascial tissue was removed and embedded in JB4 as described above. Sections $2.5 \mu \mathrm{m}$ thick were coated with a film of Ilford K2 emulsion, and developed in Kodak microdol-X at $19{ }^{\circ} \mathrm{C}$ for 4 min after an exposure time of 3 months. Sections stained with toluidine blue were observed with a light microscope.

\section{RESULTS}

\section{Light and electron microscope observations}

In the intact dorsal subfascial tissues of the mice, almost all the cells were typical fibroblasts. Most of these, spindle-like in shape, were surrounded by many collagen filaments about $40 \mathrm{~nm}$ in diameter. The rough endoplasmic reticulum and Golgi apparatus were fairly well developed in the cytoplasm.

The pellet transplanted into the subfascia looked homogeneous by light microscopy (Fig. 2a), while electron microscopy revealed that the pellet consisted of a fine fibrillar meshwork of the calf skin collagen constituent and numerous, various-sized, irregularly-shaped dense spots of the semipurified BMP component (Fig. 3).

Three days after transplantation of the BMP pellet into the dorsal subfascia, all the cells in the pellet region were typical fibroblasts (Figs. 2a, 3). They had long cytoplasmic processes, and the rough endoplasmic reticulum and Golgi apparatus were fairly well developed in the cytoplasm. The nucleus was elongated in shape, showing mild indentations with a thin

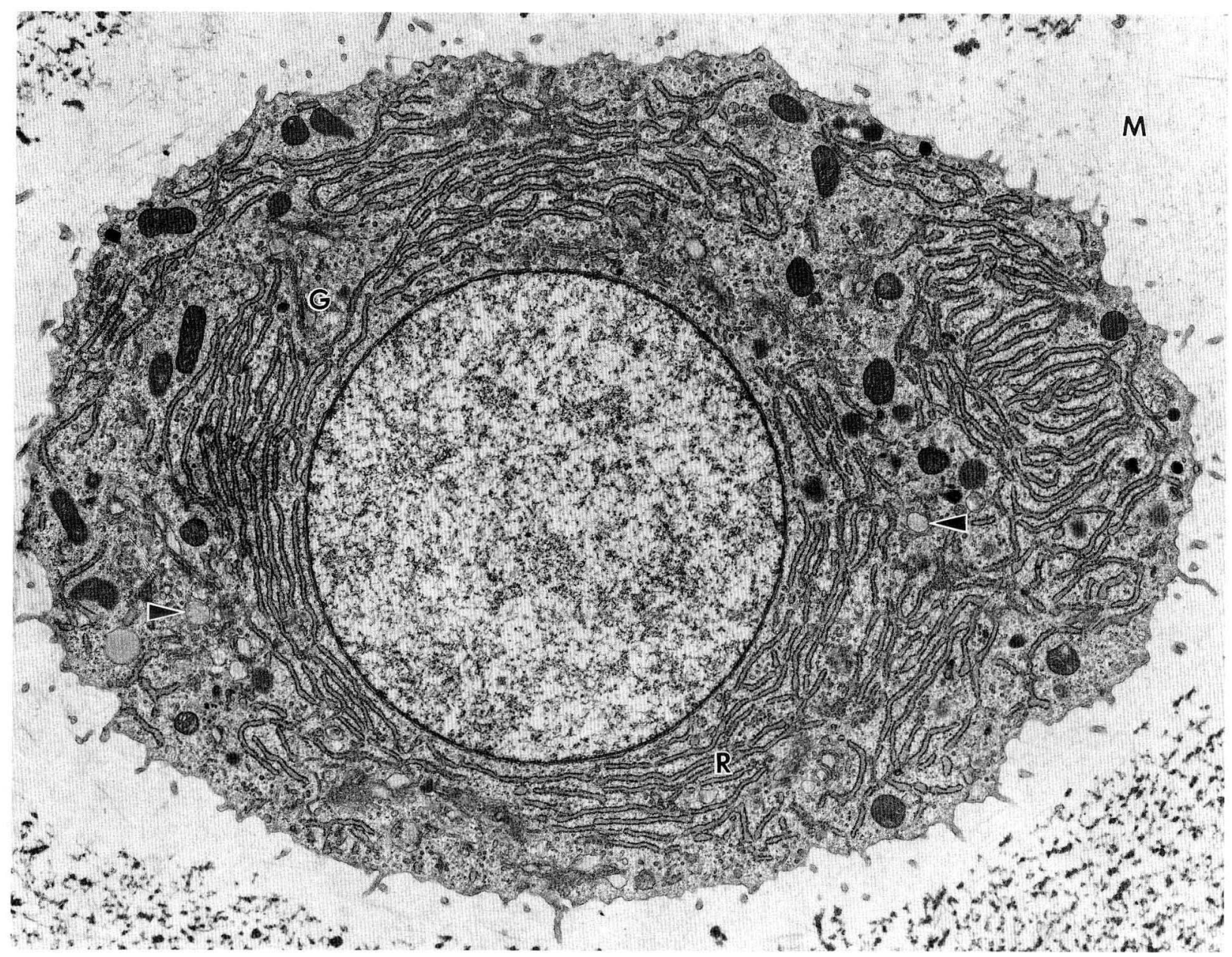

Fig. 6. Electron micrograph of a cell in the BMP pellet region at 9 days. The cell has the fine structural characteristics of the mature chondrocyte. It is oval in shape and extends many short processes into the surrounding cartilage matrix $(M)$. The rough endoplasmic reticulum $(R)$ and Golgi apparatus $(G)$ are extremely well developed and small vacuoles (arrowheads) are scattered in the cytoplasm. $\times 9,500$ 
marginal zone of dense heterochromatin. A small number of fine filaments were seen throughout the cytoplasm. Collagen filaments about $40 \mathrm{~nm}$ in diameter were frequently observed in close proximity to the cells in the pellet region.

By 5 days after implantation, the fibroblasts in the pellet region changed their shape from spindle-like to

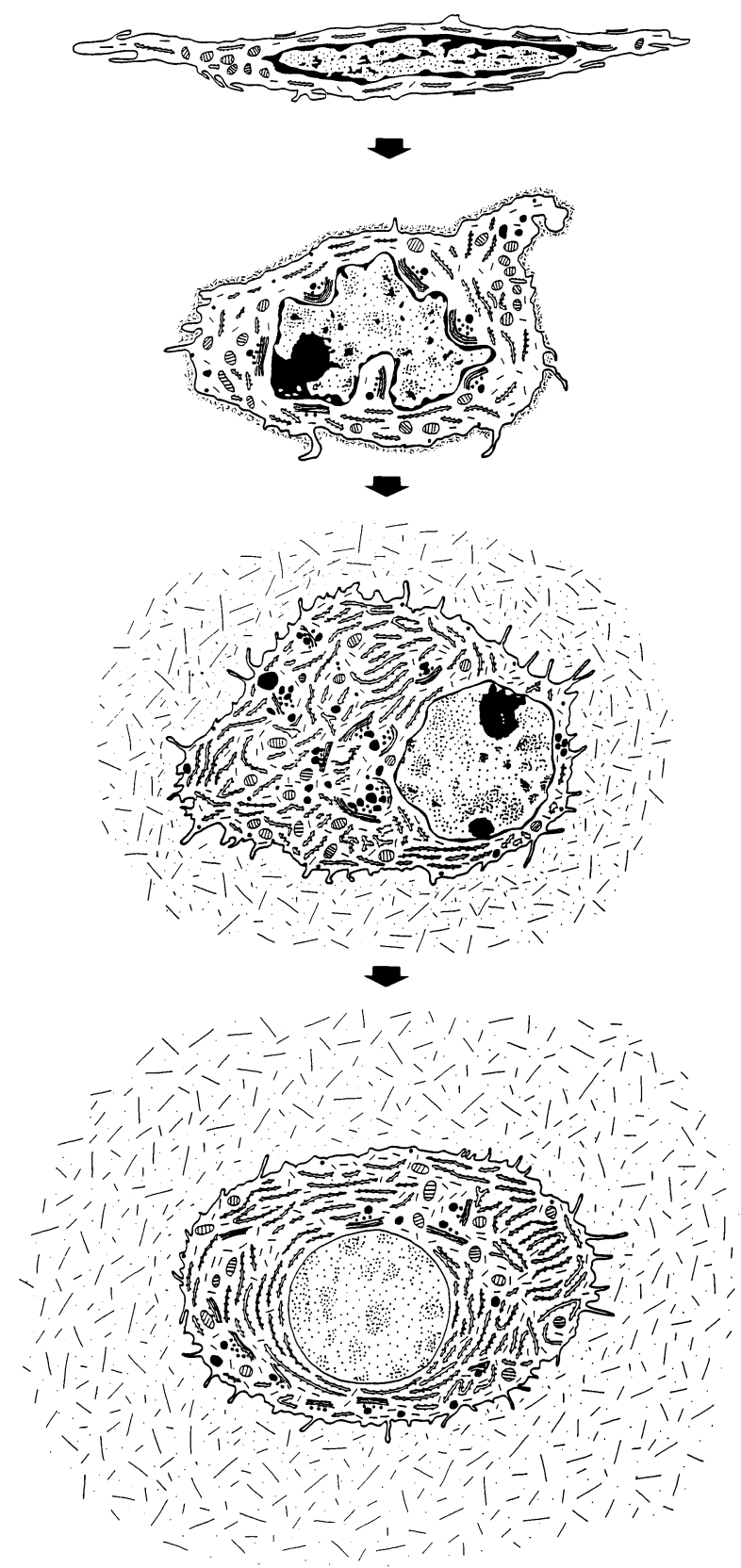

Fig. 7. Diagram showing ultrastructural aspects of the conversion of the fibroblast to the chondrocyte by bone morphogenetic protein (BMP). polygonal (Fig. 4a). The cytoplasm of the cells at 5 days was relatively scarce. The nucleus was irregularly rolled in shape, but a thin marginal layer of heterochromatin remained. The elements of rough endoplasmic reticulum and Golgi apparatus increased in number to some extent as compared with those of the fibroblasts in the pellet region at 3 days. The rough endoplasmic reticulum was scattered throughout the cytoplasm consisting of a few lamellae, and the Golgi apparatus was located circularly around the nucleus. Cytoplasmic filaments increased in number in comparison with those of the fibroblasts two days earlier. Small vacuoles $150-450 \mathrm{~nm}$ in diameter and vesicles $40-60 \mathrm{~nm}$ in diameter, containing a homogeneous substance of low electron density, appeared at 5 days in the cytoplasm. Also at 5 days, by light microscopy, a narrow area around the cells in the pellet region showed metachromasia, being stained red purple by toluidine blue. By electron microscopy, a small amount of an extracellular matrix of low electron density including a fine flocculent feltwork, which corresponded to the metachromatic region, was seen around the cells (Fig. 4b). Extrapellet tissues showed numerous typical fibroblasts.

By 7 days, the metachromatic extracellular matrix markedly increased in quantity around the cells in the pellet region (Fig. 2b). It consisted of a homogeneous substance, containing collagenous fibrils $6-20 \mathrm{~nm}$ in diameter and many electron-dense particles 10-40 $\mathrm{nm}$ in diameter (Fig. 5). The extracellular substance thus was regarded as a cartilagenous matrix.

The cells in the pellet region at 7 days, either round or polygonal in shape, extended many short processes $60-130 \mathrm{~nm}$ in width into the surrounding matrix. By electron microscopy the cytoplasm looked relatively dense due to the remarkable development of cell organelles and an increase in number of cytoplasmic filaments (Fig. 5). The elements of rough endoplasmic reticulum remarkably increased in number by 7 days as compared with those of the cells two days earlier, and they were distributed throughout the cytoplasm. The elements of Golgi apparatus were also well developed and were located at random in the cytoplasm. Small cytoplasmic vacuoles and vesicles, containing a homogeneous substance of low electron density, greatly increased in number by 7 days in comparison with those of the cells at 5 days. Some of the vacuoles and vesicles were located in the peripheral cytoplasm, and some of them were open to the extracellular space. The nucleus became round and mildly indented by 7 days, and the marginal heterochromatin layer of the nucleus was not so prominent.

Nine days after transplantation of the pellet, almost all the cells in the pellet region showed the 
characteristics of the mature chondrocyte (Figs. 2c, 6). They were oval or round in shape and surrounded by an abundant extracellular matrix, showing a strong metachromatic reaction to toluidine blue. By electron microscopy, a small number of collagen fibrils about $20 \mathrm{~nm}$ in diameter were usually seen in the extracellular cartilage matrix in addition to thinner fibrils. The cells extended many short processes into the surrounding matrix. The cytoplasm was occupied by abundant organelles and many cytoplasmic filaments, and looked dense by electron microscopy. The nucleus was round in shape with evenly distributed chromatin. The elements of rough endoplasmic reticulum, comprising several parallel lamellae, were distributed throughout the cytoplasm, surrounding the nucleus. The Golgi apparatus was scattered in the cytoplasm. A large number of small vacuoles and vesicles were also seen in the cytoplasm. Mitochondria, oval- or rod-shaped with lamellar cristae, did not change in morphology during the conversion of the fibroblast to the mature chondrocyte (Fig. 7).

During the experiment, the so-called undifferentiated mesenchymal cells which are usually seen in the embryo, characterized by poorly-developed cell organelles and by numerous free ribosomes, were never identified in the subfascial tissue.

In the control animals, the cells seen in the region of the pellet consisting only of collagen fibers without BMP, showed the characteristics of a typical fibroblast even 7 days after transplantation of the pellet. They were elongated in shape. The nucleus was heterochromatic, and the cell organelles such as rough endoplasmic reticulum and Golgi apparatus were fairly well developed. Collagen fibrils with striation about $40 \mathrm{~nm}$ in diameter were often seen around the cells. Neither a metachromatic reaction nor an extracellular cartilagenous matrix was recognized.

\section{Light microscopic autoradiography of ${ }^{35} \mathrm{~S}$}

Three days after transplantation of the BMP pellet, the silver grains for ${ }^{35} \mathrm{~S}$ were very difficult to recognize over the fibroblasts in the pellet region as well as over the outside of the pellet $3 \mathrm{~h}$ after injection of ${ }^{35} \mathrm{~S}$ (Fig. 8a).

At 5 days, many grains were seen not only over the polygonal or round cells in the pellet region, but also over the extracellular matrix around the cells, showing a metachromatic reaction to toluidine blue (Fig. 8b). At high magnification it was clear that the grains were specifically accumulated over the juxtacellular zone (Fig. 8c). The fibroblasts in the extrapellet region, however, were essentially free of the grains.

\section{DISCUSSION}

Chondrocytes have been believed by many investigators to be derived from undifferentiated mesenchymal cells even in the post-fetal life. Undifferentiated mesenchymal cells having a potency to

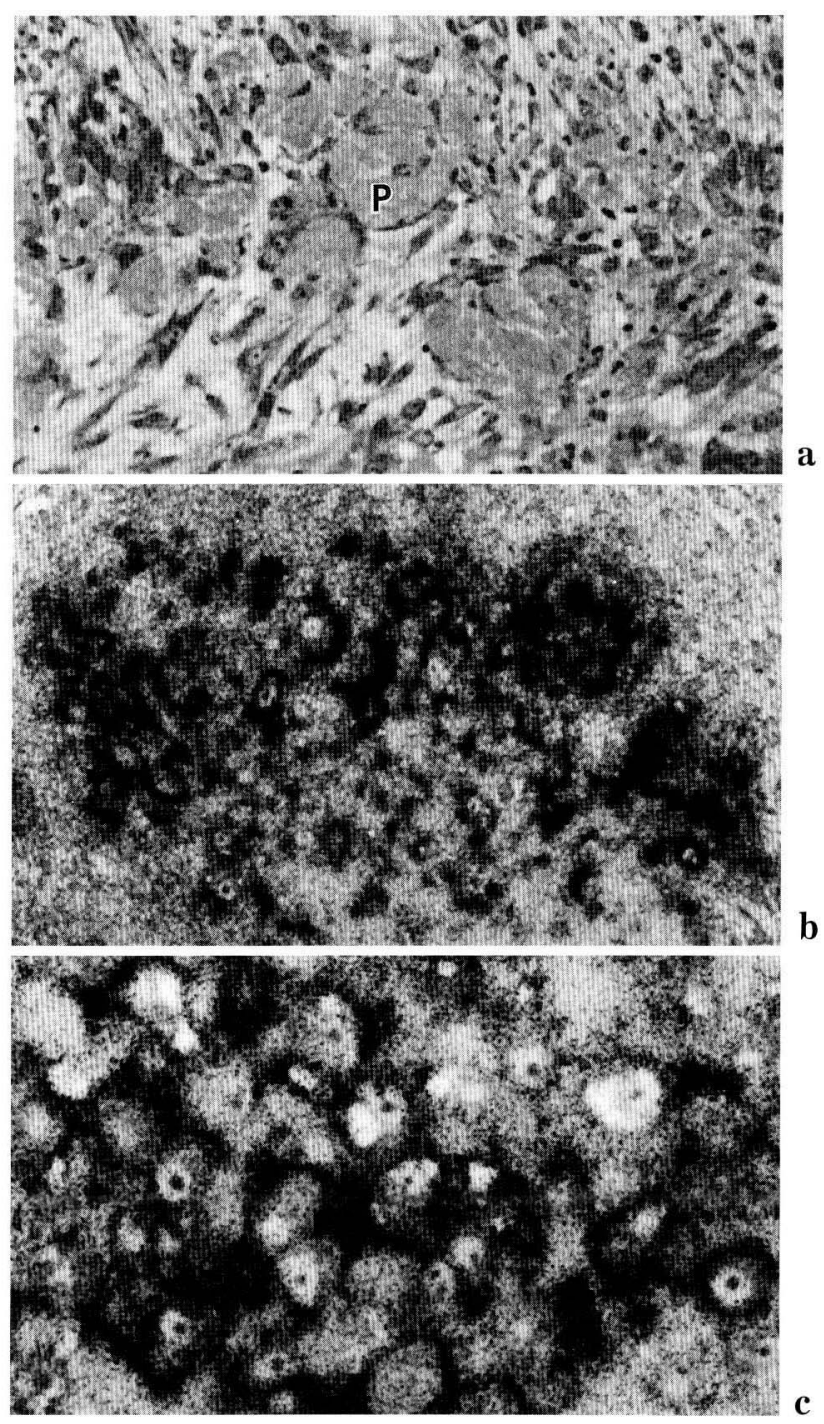

Fig. 8. Light microscopic radioautograms of ${ }^{35} \mathrm{~S}$.

a. Three days after transplantation of the pellet consisting of semipurified BMP, the silver grains are difficult to recognize over the fibroblasts within the pellet region $(P)$ $3 \mathrm{~h}$ after injection of ${ }^{35} \mathrm{~S} . \times 180$. b. At 5 days, many grains are seen over the cells in addition to the extracellular matrix around the cells in the pellet region. $\times 180$. c. High magnification of the pellet region at 5 days. The grains are especially accumulated over the juxtacellular zone. $\times 430$ 
differentiate into various kinds of connective tissue cells, including chondrocytes, osteocytes and blood cells, have been supposed to persist in the connective tissue-especially pericapillary region-even in adult animals. Actually, however, it is difficult to find, in the connective tissue of adult animals, a typical undifferentiated mesenchymal cell under the electron microscope, which is characterized by poorly-developed rough endoplasmic reticulum and by numerous free ribosomes. In this communication we have demonstrated that the fibroblast is directly convertible to the chondrocyte by light as well as electron microscope observation of the fibrous connective tissue where bone morphogenetic protein (BMP) was implanted.

Typical fibroblasts in the BMP pellet region became mature chondrocytes by 9 days. The cells in the BMP pellet region were typical fibroblasts at 3 days and considered to change to chondroblasts by 5 days in light of the following findings: First, small vacuoles containing a homogeneous material of low electron density, characteristic of the chondrocyte, appeared in the cytoplasm, and the metachromatic extracellular matrix was observed around the cell. Second, autoradiographic study of ${ }^{35} \mathrm{~S}$ revealed the uptake of sulfur by the cell and its strong accumulation around the cell, implying the active production of a cartilage matrix rich in proteoglycan. Therefore, the transformation of the fibroblast to the chondroblast is considered to occur at least by 5 days after implantation.

The authors agree in principle with the observations by REDDI and ANDERSON (1976) that the fibroblast transforms to a chondrocyte when decalcified bone particles are transplanted into the rat subcutaneous tissue. However, the detailed process of this conversion was not shown in their paper.

In addition, the fibroblast has been reported to have the potential to become several other kinds of cells in the post-fetal life. NAPOLITANO (1963) showed by electron microscopy its conversion to the adipose cell in the epididymal fat pad of rats. More recently, HIURA and FUJITA (1977) reported that the fibroblast is convertible to the theca interna gland cell (steroidsecreting cell) in the mouse ovary. Therefore, the fibroblast is considered to have the potential to change into a chondrocyte, adipocyte, and steroidproducing cell in response to certain local influences.
Analysis of the genetic events such as the changes of gene expression during the differentiation of the fibroblast into different cell types remains to be clarified, and it might make an important contribution to the solution of cell differentiation, one of the major problems in cell biology.

In conclusion, the present paper has convincingly demonstrated the process of direct conversion of fibroblasts to chondrocytes, and added example of the potentiality of fibroblasts being changeable to different cell types.

\section{REFERENCES}

Amitani, K., Y. Nakata and J. Stevens: Bone induction by lyophilized osteosarcoma in mice. Calcif. Tiss. Res. 16: 305-313 (1974).

Hiura, M. and H. Fujita: Electron microscopy of the cytodifferentiation of the theca cell in the mouse ovary. Arch. Histol. Jap. 40: 95-105 (1977).

Napolitano, L.: The differentiation of white adipose cells. An electron microscope study. J. Cell Biol. 18: 663679 (1963).

Reddi, A. H. and W. A. Anderson: Collagenous bone matrix-induced endochondral ossification and hemopoiesis. J. Cell Biol. 69: 557-572 (1976).

Takaoka, K., H. Yoshikawa, N. Shimizu, K. Ono, K. Amitani and Y. Nakata: Purification of a boneinducing substance (osteogenic factor) from a murine osteosarcoma. Biomed. Res. 2: 466-471 (1981).

TaKaOKa, K., H. NaKahara, H. Yoshikawa, K. MasUhaRA, T. TSUDA and K. ONo: Ectopic bone induction on and in porous hydroxyapatite combined with collagen and bone morphogenetic protein. Clin. Orthoped. 234: 250-254 (1988).

Prof. Hisao Fujita

Department of Anatomy

Osaka University Medical School

2-2 Yamadaoka, Suita-city

Osaka-fu, 565 Japan

藤田尚男

565 大阪府吹田市山田丘 2-2

大阪大学医学部

解剖学教室 